\title{
Ichthyosis as a paraneoplastic syndrome and atypical variant of mycosis fungoides: two cases report
}

\author{
Małgorzata Sokołowska-Wojdyło ${ }^{1}$, Marta Malek ${ }^{1}$, Hanna Majewska², Roman Nowicki ${ }^{1}$, Jadwiga Roszkiewicz ${ }^{1}$
}

1Department of Dermatology, Venereology and Allergology, Medical University of Gdansk, Poland Head: Prof. Roman Nowicki MD, PhD

2Department of Pathomorphology, Medical University of Gdansk, Poland

Head: Prof. Wojciech Biernat MD, PhD

Postep Derm Alergol 2012; XXIX, 6: 467-470

DOI: 10.5114/pdia.2012.32396

\begin{abstract}
Acquired ichthyosis is a known paraneoplastic sign of lymphoproliferative malignancies, but ichthyosiform eruption can also constitute a rare atypical variant of mycosis fungoides. Ichthyosiform mycosis fungoides differs from acquired ichthyosis associated with mycosis fungoides in histopathology. Histological pictures of paraneoplastic ichthyosis usually do not show any aspect related to malignancy in the skin. In both cases thinning of the granular layer and decrease of filaggrin in that layer are observed. We describe here 2 patients with mycosis fungoides, who were treated in the Department of Dermatology, the first one with ichthyosiform mycosis fungoides and the other one with acquired ichthyosis with coexisting mycosis fungoides.
\end{abstract}

Key words: mycosis fungoides, ichthyosis, paraneoplastic syndrome.

\section{Introduction}

Mycosis fungoides (MF) is the most common primary cutaneous lymphoma. The disease usually affects people in middle age (40-50 years), with a predominance for the male gender (M/F: $2: 1)$ [1-4]. Apart from the classic Alibert-Bazen type of MF, with typical skin lesions: patches, plaques and tumors, many atypical variants have been reported (Table 1) [5].

The ichthyoses are a heterogeneous group of cutaneous keratinization disorders. The symptoms consist of pityroid and rhomboid scales on the skin with severe dryness $[6,7]$. Acquired ichthyosis (AI) in contrast to the congenital type is not a syndrome but a clinical sign of many systemic diseases, including malignant, infectious, autoimmune and endocrine disorders, as well as metabolic conditions and medications (Table 2) [8].

Ichthyosiform skin lesions can coexist with MF or constitute a very rare atypical variant of this disease. Two patients with MF, who were treated in the Department of Dermatology, will be presented: one with an ichthyosiform type of MF (IMF), and the other with Al with coexisting MF.

\section{Case reports}

Case 1

A 71-year-old man, with hypertension, was admitted to the Department of Dermatology because of 20 years' erythematosus scaling lesions. The ichthyosiform lesions were spread on the trunk, arms and legs (Figure 1). Clinical examination did not show enlarged lymph nodes and organomegaly. Histological features of biopsy from abdominal scaling skin lesions revealed orthokeratosis, thinning of the granular layer and infiltration of atypical cells into the epidermis and the superficial dermis (Figure 2). Immunohistochemical studies demonstrated that most infiltrated atypical lymphocytes were CD4, CD8 was positive focally. The results of the routine blood investigations were normal. Chest-X-ray examination and abdomen ultrasonography revealed no abnormalities. The diagnosis of MF, stage IB (T2NOMO), was established. The patient was treated with ultraviolet light B 311 therapy three times a week. After 5 months of treatment the ichthyosiform eruption regressed and pruritus decreased.

\section{Case 2}

A 69-year-old male patient, with glaucoma, cataract and prostatic hypertrophy, was referred to the Department of Dermatology because of erythematosus lesions on the trunk and lower leg with pruritus lasting for 6 months (Figure 3). Additionally, the patient has suffered from severe dryness of the skin with scaling on the surface for 5 years, what was diagnosed as acquired ichthyosis without any known etiology (Figure 4). He did not take any medicaments 
Table 1. Clinicopathological variants of mycosis fungoides

\begin{tabular}{|c|}
\hline Acanthosis nigricans-like mycosis fungoides \\
\hline Angiocentric/angiodestructive mycosis fungoides \\
\hline Bullous (vesiculobullous) mycosis fungoides \\
\hline Dyshidrotic mycosis fungoides \\
\hline Erythrodermic mycosis fungoides \\
\hline Follicular (pilotropic) mycosis fungoides \\
\hline Granulomatous mycosis fungoides \\
\hline Granulomatous slack skin syndrome \\
\hline Hyperpigmented mycosis fungoides \\
\hline Hypopigmented mycosis fungoides \\
\hline Ichthyosis-like mycosis fungoides \\
\hline Interstitial mycosis fungoides \\
\hline 'Invisible’ mycosis fungoides \\
\hline Mucinous mycosis fungoides \\
\hline Mycosis fungoides palmaris et plantaris \\
\hline Mycosis fungoides with eruptive infundibular cysts \\
\hline Mycosis fungoides with follicular mucinosis \\
\hline Mycosis fungoides with large-cell transformation \\
\hline Pagetoid reticulosis (Woringer-Kolopp type) \\
\hline Papular mycosis fungoides \\
\hline Papuloerythroderma of Ofuji \\
\hline Perioral dermatitis-like mycosis fungoides \\
\hline Pigmented purpura-like mycosis fungoides \\
\hline $\begin{array}{l}\text { Poikilodermatous mycosis fungoides (poikiloderma vasculare } \\
\text { atrophicans) }\end{array}$ \\
\hline Pustular mycosis fungoides \\
\hline Small-plaque parapsoriasis \\
\hline Syringotropic mycosis fungoides \\
\hline Unilesional (solitary) mycosis fungoides \\
\hline Verrucous/hyperkeratotic mycosis fungoides \\
\hline Zosteriform mycosis fungoides \\
\hline
\end{tabular}

inducing ichthyosis. The diseases, including infections, solid tumors, kidney diseases, hypothyroidism, and nutritional deficiencies were ruled out. There were no peripheral lymphadenopathy or organomegaly. Histopathological examination of two skin biopsies from erythematosus lesions revealed mycosis fungoides with infiltration of atypical lymphocytes CD 3+, CD 4+, CD 8+, CD 5+ and CD 20- (Figure 5). The biopsy from ichthyosiform eruptions disclosed hyperkeratosis and parakeratosis without infiltration of atypical cells typical of MF (Figure 6). Laboratory and imaging studies revealed no significant aberrations. The diagnosis
Table 2. Causes of acquired ichthyotic skin lesions

\begin{tabular}{|c|c|}
\hline Category & Disorders \\
\hline \multirow[t]{4}{*}{ Paraneoplastic } & Hodgkin lymphoma \\
\hline & Other lymphomas \\
\hline & Kaposi sarcoma \\
\hline & Other malignancy \\
\hline \multirow[t]{3}{*}{ Infections } & Leprosy \\
\hline & Tuberculosis \\
\hline & HIV/AIDS \\
\hline \multirow[t]{2}{*}{ Nutritional deficiencies } & Pellagra \\
\hline & Vitamin A deficiency \\
\hline \multirow[t]{6}{*}{ Medicaments } & Statins \\
\hline & Nicotinic acid \\
\hline & Allopurinol \\
\hline & Cimetidine \\
\hline & Lithium \\
\hline & Retinoids \\
\hline \multirow[t]{4}{*}{ Others } & Crohn's disease \\
\hline & Down's syndrome \\
\hline & Hypothyroidism \\
\hline & Kidney diseases \\
\hline
\end{tabular}

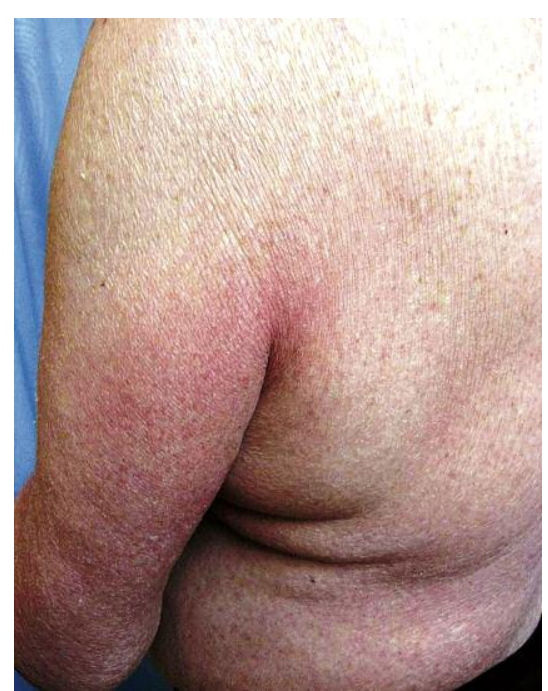

Figure 1. Case 1. Erythematosus, scaling skin lesions on the trunk and left arm diagnosed as IMF

of MF, stage IB (T2NOMO) and paraneoplastic ichthyosis was established. The patient was treated with ultraviolet light B 311 therapy three times a week. After 5 months of treatment the remission of erythematosus lesions as well as ichthyosiform changes was observed. 


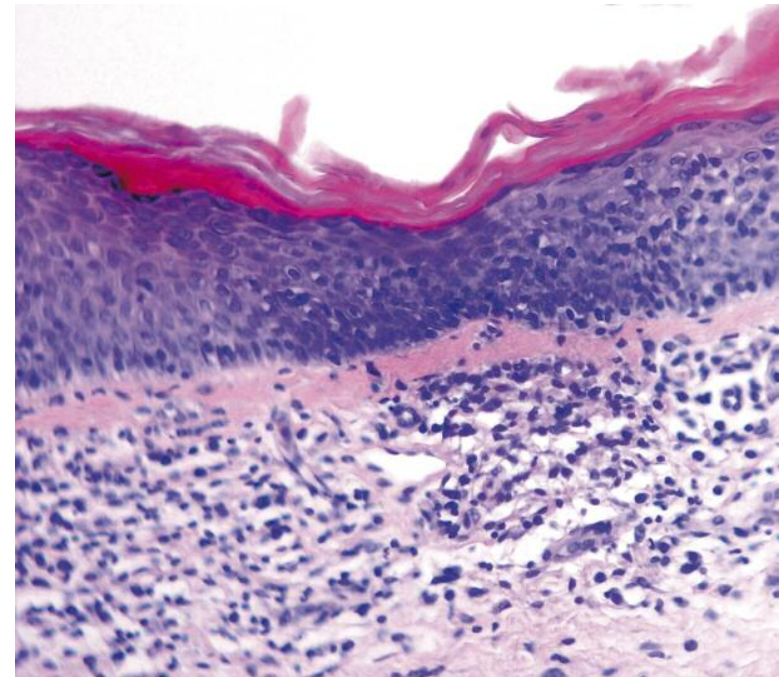

Figure 2. Case 1. Histopathologic findings of ichthyosiform eruption: orthokeratosis, thinning of the granular layer, mild acanthosis, abundant infiltration of mononuclear cells (lymphocytes, histiocytes, atypical cells) into the epidermis and the superficial dermis. $\mathrm{H}+\mathrm{E}, 40 x$

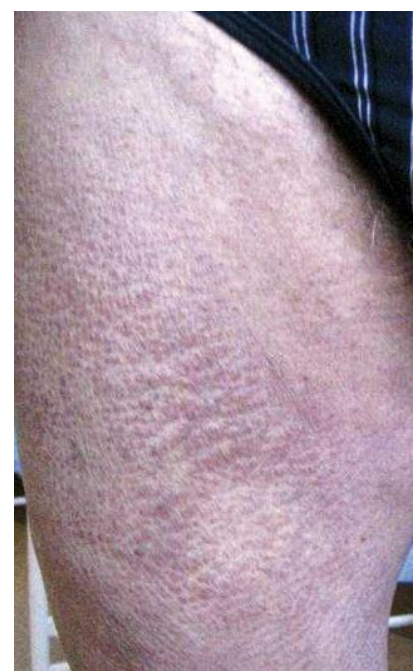

Figure 4. Case 2. Scaling skin lesions on the right thigh diagnosed as Al

\section{Discussion}

Among the malignant diseases known to be associated with ichthyosiform skin lesions, lymphoproliferative neoplasms are reported most often [6]. Morizane et al., during 5 years' observation of 106 patients with malignant lymphoma found 9 with ichthyosiform skin lesions including 3 of 10 patients with anaplastic large cell lymphoma (ALCL) and 6 of 44 patients with MF. None of the 18 observed patients with cutaneous B-cell lymphoma had ichthyosiform eruptions [9]. Also the complication of ichthyosiform

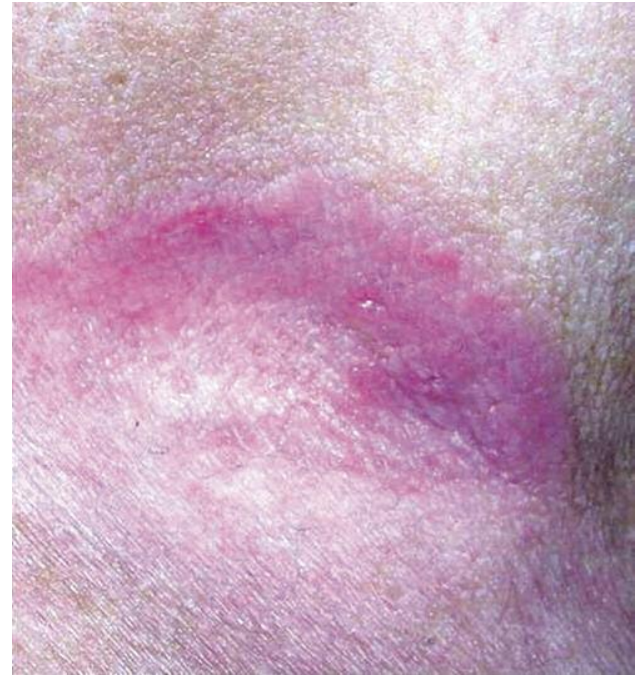

Figure 3. Case 2. Erythematosus skin lesion in the armpit area diagnosed as MF

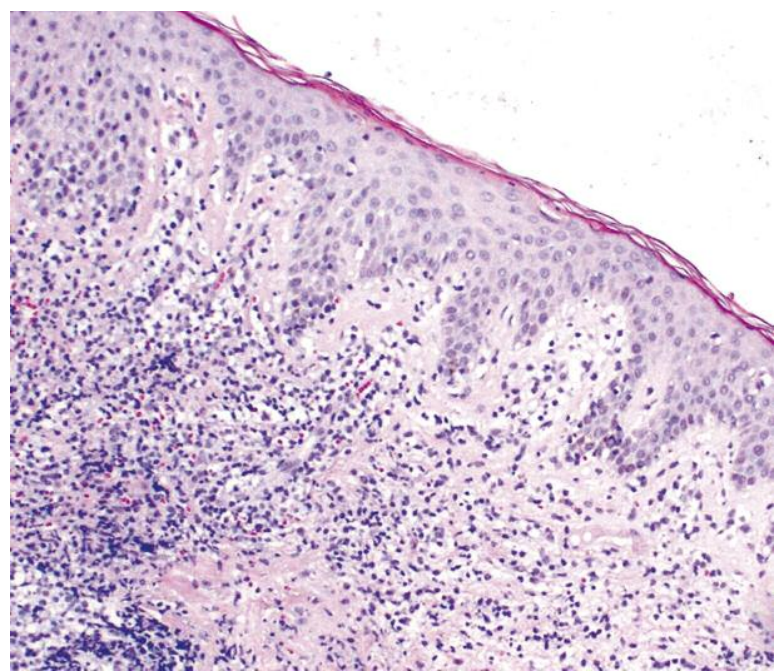

Figure 5. Case 2. Histopathologic findings of erythematosus lesions: Abundant infiltration of atypical lymphocytes into the dermis. $\mathrm{H}+\mathrm{E}, 10 \times$

eruptions in cutaneous B-cell lymphoma has not thus far been reported in the English literature.

Ichthyosiform type of MF differs from Al associated with MF in histopathology. We distinguish AI, IMF and the overlap of Al and IMF. Acquired ichthyosis demonstrated packed orthohyperkeratosis mimicking ichthyosis vulgaris, without lymphocytic infiltrates. Ichthyosiform type of MF showed epidermotropic infiltration of atypical lymphocytes without ichthyosis vulgaris-like packed hyperkeratosis. The overlap of Al and IMF discloses both packed hyperkeratosis and epidermotropic infiltration of atypical lymphocytes. 


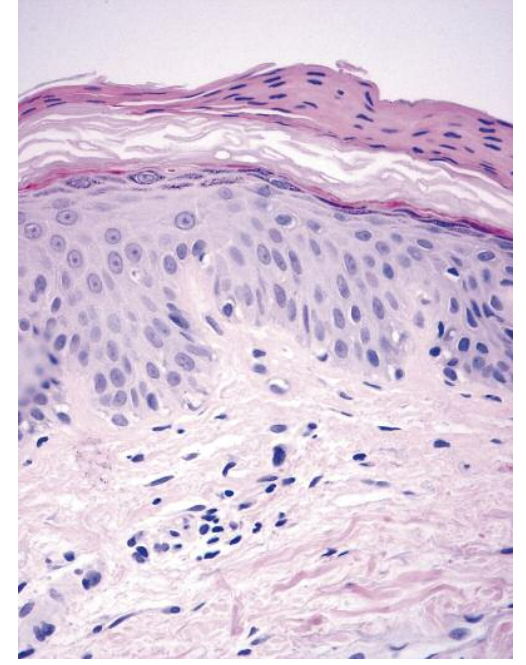

Figure 6. Case 2. Histopathologic findings of scaling lesions: packed hyperkeratosis with marked parakeratosis. No infiltration of atypical lymphocytes is present. $\mathrm{H}+\mathrm{E}, 40 x$

In all three situations, thinning of the granular layer is observed. Also an expression of filaggrin, a key protein involved in the terminal differentiation of the epidermis and formation of the skin barrier, in the granular layers is markedly diminished in all three cases, what is typical of ichthyosis vulgaris [9].

Ichthyosiform type of MF is a very rare atypical variant of this disease, arising in 1.8-3.5\% of MF patients [10, 11]. According to the clinical findings, IMF can be divided into 3 types: as the sole manifestation of the disease, in conjunction with additional atypical findings of MF and in combination with the classic types of MF [12]. Among cases presented by Morizane et al. [9], diagnosis of IMF should be only considered when it is the sole manifestation of MF, as in our first case.

Acquired ichthyosis, as a paraneoplastic syndrome, may precede by 2 weeks - 10 years the diagnosis of the malignancy. Prolonged intervals were especially documented in the lymphoproliferative diseases [6]. The interval between ichthyosis and MF was 5 years in our second patient.

Authors suggest that $\mathrm{Al}$ is a frequent complication of CD 30+ lymphoproliferative disorders, such as Hodgkin Lymphoma CD 30+, ALCL or lymphomatoid papulosis. Those observations confirm Morizane et al. in their series. Acquired ichthyosis was diagnosed in five of nine patients with ichthyotic eruptions. Three of these patients had $\mathrm{ALCL}$ and 2 had MF (stage IVa and IIb) with CD 30+ atypical lymphocytes in tumors [9].

Clinical remission in IMF is obtained with nonaggressive therapies such as topical treatments, PUVA therapy and Ultraviolet light B (UVB) $[12,13]$. A significant remission was observed, after 5 months of UVB 311 therapy 3 times a week in the case of our first patient. In the situation when MF coexists with ichthyosis, 1-6 months' treat- ment of the underlying malignant disease results in healing of ichthyosis in most cases [6], as occurred in our second case. It confirms ichthyosis as a paraneoplastic syndrome.

Ichthyotic skin lesions can indicate the presence of a severe underlying disease or reveals an atypical form of MF, and thus always requires careful diagnosis and follow-up.

\section{References}

1. Sokołowska-Wojdyło M, Maciejewska-Radomska A, Trzeciak M, et al. Results of the treatment primary cutaneous lymphomas in the Department of Dermatology Medical University in Gdansk performed in years 1997-2008. Dermatol Klin 2009; 11: 141-6.

2. Wojewoda K, Brenner J, Sokołowska-Wojdyło M, BarańskaRybak M. Treatment of primary cutaneous lymphoma with reference to the latest therapeutic consensus of the Polish Lymphoma Research Group (PLRG). Post Dermatol Alergol 2012; 28: 63-8.

3. Sikorska M, Sokołowska-Wojdyło M, Kowalczyk A, Roszkiewicz J. Effectiveness of interferon alpha in mycosis fungoides therapy. Post Dermatol Alergol 2012; 28: 51-5.

4. Olek-Hrab K, Osmola Mańkowska A, Silny W, et al. Use of UVA1 in the treatment of mycosis fungoides. Post Dermatol Alergol 2011; 27: 158-64.

5. Requena L, González-Guerra E, Angulo J, et al. Anetodermic mycosis fungoides: a new clinicopathological variant of mycosis fungoides. Br J Dermatol 2008; 158: 157-62.

6. Levy $\mathrm{O}$, Tishler M. Acquired ichthyosis as the primary manifestation of renal cell carcinoma. Isr Med Assoc J 2009; 11: 121-2.

7. Rabhi M, Ennibi K, Harket A, et al. Acquired ichthyosis disclosing non-Hodgkin's malignant lymphoma. Intern Med 2007; 46: 397-9.

8. Oji V. Keratinization disorders. In: Braun-Falco Dermatology. Burgdorf WHC, Plewig G, Wolff HH, Landthaler M (eds.). Czelej, Lublin 2011; 839-74.

9. Morizane S, Setsu N, Yamamoto T, et al. Ichthyosiform eruptions in association with primary cutaneous T-cell lymphomas. Br J Dermatol 2009; 161: 115-20.

10. Marzano AV, Borghi A, Facchetti M, Alessi E. Ichthyosiform mycosis fungoides. Dermatology 2002; 204: 124-9.

11. Hodak E, Amitay I, Feinmesser M, et al. Ichthyosiform mycosis fungoides: an atypical variant of cutaneous T-cell lymphoma. I Am Acad Dermatol 2004; 50: 368-74.

12. Nam KH, Park J, Hong JS, et al. Mycosis fungoides as an ichthyosiform eruption. Ann Dermatol 2009; 2: 182-4.

13. Badawy E, D'Incan M, El Majjaoui S, et al. Ichthyosiform mycosis fungoides. Eur J Dermatol 2002; 12: 594-6. 